\title{
Predictors of health workers' knowledge about artesunate-based severe malaria treatment recommendations in government and faith-based hospitals in Kenya
}

Beatrice Machini ${ }^{1,2^{*}} \mathbb{D}$, Dejan Zurovac ${ }^{3,4}$, Beatrice Amboko ${ }^{3}$, Lucas Malla ${ }^{3}$, Robert W. Snow ${ }^{3,4}$, Hillary Kipruto ${ }^{1,5}$ and Thomas N. O. Achia ${ }^{1,6}$

\begin{abstract}
Background: Health workers' knowledge deficiencies about artesunate-based severe malaria treatment recommendations have been reported. However, predictors of the treatment knowledge have not been examined. In this paper, predictors of artesunate-based treatment knowledge among inpatient health workers in two hospital sectors in Kenya are reported.

Methods: Secondary analysis of 367 and 330 inpatient health workers randomly selected and interviewed at 47 government hospitals in 2016 and 43 faith-based hospitals in 2017 respectively, was undertaken. Multilevel ordinal and binary logistic regressions examining the effects of 11 factors on five knowledge outcomes in government and faith-based hospital sectors were performed.

Results: Among respective government and faith-based health workers, about a third of health workers had high knowledge of artesunate treatment policies (30.8\% vs $32.9 \%$ ), a third knew all dosing intervals (33.5\% vs $33.3 \%$ ), about half knew preparation solutions ( $49.9 \%$ vs 55.8\%), half to two-thirds knew artesunate dose for both weight categories (50.8\% vs $66.7 \%$ ) and over three-quarters knew the preferred route of administration (78.7\% vs $82.4 \%)$. Eight predictors were significantly associated with at least one of the examined knowledge outcomes. In the government sector, display of artesunate administration posters, paediatric ward allocation and repeated surveys were significantly associated with more than one of the knowledge outcomes. In the faith-based hospitals, availability of artesunate at hospitals and health worker pre-service training were associated with multiple outcomes. Exposure to in-service malaria case-management training and access to malaria guidelines were only associated with higher knowledge about artesunate treatment policy.

Conclusion: Programmatic interventions ensuring display of artesunate administration posters in the wards, targeting of health workers managing adult patients in the medical wards, and repeated knowledge assessments are likely to be beneficial for improving the knowledge of government health workers about artesunate-based severe malaria treatment recommendations. The availability of artesunate and focus on improvements of nurses' knowledge should be prioritized at the faith-based hospitals.
\end{abstract}

*Correspondence: bkemunto2002@gmail.com

${ }^{1}$ University of Nairobi, Institute of Tropical and Infectious Diseases, Nairobi, Kenya

Full list of author information is available at the end of the article

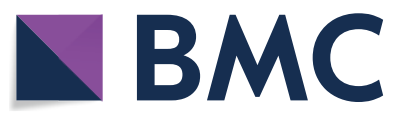

(c) The Author(s) 2020. This article is licensed under a Creative Commons Attribution 4.0 International License, which permits use, sharing, adaptation, distribution and reproduction in any medium or format, as long as you give appropriate credit to the original author(s) and the source, provide a link to the Creative Commons licence, and indicate if changes were made. The images or other third party material in this article are included in the article's Creative Commons licence, unless indicated otherwise in a credit line to the material. If material is not included in the article's Creative Commons licence and your intended use is not permitted by statutory regulation or exceeds the permitted use, you will need to obtain permission directly from the copyright holder. To view a copy of this licence, visit http://creativeco mmons.org/licenses/by/4.0/. The Creative Commons Public Domain Dedication waiver (http://creativecommons.org/publicdomain/ zero/1.0/) applies to the data made available in this article, unless otherwise stated in a credit line to the data. 
Keywords: Artesunate, Knowledge, Severe malaria, Predictors

\section{Background}

Despite a falling prevalence of Plasmodium falciparum infection [1,2] severe malaria is a common cause of admission in Kenyan hospitals [3]. Alongside the World Health Organization (WHO) recommendation in 2012 [4], Kenya was among the first African countries to adopt the artesunate treatment policy for severe malaria [5]. The Division of National Malaria Programme revised national malaria guidelines to reflect the new policy, procured and facilitated distribution of injectable artesunate to health facilities, developed training curriculums and job aids around new case-management standards, and implemented inservice training programs to facilitate readiness of clinicians and nurses to deliver new treatment standards [6, 7]. Of estimated 400 public hospitals in the country, about three-quarters are government-owned and the remaining are faith-based organization (FBO) hospitals [8]. National artesunate implementation equally targeted government and FBO health workers, but subsidized artesunate was available only to the government hospitals procuring medicines through the Kenya Medical Supply Agency.

According to the national guidelines [5], artesunate is the recommended treatment for all patient populations with severe malaria including pregnant women across all trimesters of the pregnancy. The recommended dose is $3 \mathrm{mg} /$ $\mathrm{kg}$ for children below $20 \mathrm{~kg}$ and $2.4 \mathrm{mg} / \mathrm{kg}$ for patients above $20 \mathrm{~kg}$. For the inpatient management, the preferred route of artesunate administration is intravenous with 12 hourly dosing intervals between the first three doses. After the minimum of three parenteral doses artesunate should be continued at 24 hourly dosing intervals until the patient is able to take oral anti-malarial therapy.

Health workers' knowledge about new treatment policy and recommended use of the new medicines is one of the basic pre-requisites determining the readiness of the health system to implement any drug policy [9-11]. Several studies have suggested major knowledge deficiencies about artesunate-based treatment recommendations [12, 13], but no study has examined predictors of the health workers' knowledge. This study examined the predictors of the inpatient health workers' knowledge about artesunate-based severe malaria treatment recommendations in government and FBO hospitals in Kenya.

\section{Methods}

\section{Data sources}

The secondary analysis of two rounds of cross-sectional, inpatient malaria case-management surveys undertaken at government hospitals in 2016 and two rounds of the cross-sectional surveys undertaken in 2017 at the FBO hospitals was performed. All of 47 Kenyan Counties with a government referral hospital and 43 of 47 Counties with a major FBO hospital (four Counties did not have a FBO hospital) were included. Of 90 surveyed hospitals across both sectors, 26 are in high malaria risk areas around the Lake Victoria and along the Indian Ocean coast while the remaining 64 hospitals are within the low risk areas [2, 14]. All hospital surveys applied the same methodologies and the details have been previously published [12]. Of relevance for predictors of the health workers knowledge, interviews with randomly sampled clinician and nurse on duty during the day shift in each of the admission wards of interest (paediatric and combined medical wards) were undertaken following fishbowl (out of hat) sampling technique. During the interviews data on health worker's demographics, exposure to in-service trainings, guidelines, supportive supervision, and their knowledge about management of severe malaria were collected. The knowledge component was assessed using selfadministered, multiple choice questions. The interviews were undertaken by experienced external hospital nurses trained in the week prior to data collection and using pre-tested data collection form upon obtaining written informed consent from the participant. Regarding the hospital level factors, they included the physical assessments of the non-expired artesunate at the pharmacy and the presence of displayed artesunate administration posters in the wards. Upon the completion of the interviews and knowledge assessments, all participating health workers were informed about the correct responses, given national malaria case-management guidelines, and if absent, distributed artesunate administration posters to be displayed on the walls.

\section{Knowledge outcomes and definitions}

Five knowledge outcomes reflecting severe malaria treatment recommendations based on artesunate use were selected. The outcomes reflected the correctness of health workers' knowledge about (1) severe malaria treatment policy, (2) artesunate dose, (3) dosing intervals, (4) artesunate preparation, and (5) preferred route of artesunate administration. All outcomes were categorized on three-point scale into high, medium and low knowledge levels with an exception of the preferred route of administration which had two levels of the categorization. The definitions of the knowledge categories for each outcome assessed are provided in Table 1. 


\section{Statistical analysis}

Descriptive analyses, disaggregated by predictor variables, were undertaken using frequencies and percentages for each of the five outcomes. To examine health worker and health facility factors associated with health workers' knowledge about severe malaria treatment, multilevel ordinal and binary logistic regression models were used for four ordinal and one binary outcomes respectively (Table 1). The examined health worker level factors included gender, age, pre-service training, ward allocation, and exposure to malaria guidelines, in-service malaria case-management training and supportive supervision. While the hospital-level factors included the availability of artesunate during the survey, display of artesunate administration posters and endemicity. Multilevel modelling approach was adopted to account for clustering of health workers within the hospitals. Candidate predictor variables were selected using unadjusted regression models for each outcome, with multicollinearity tested between those that had $P$-values $<0.15$. To obtain adjusted estimates, the selected variables were included in multivariable regression models. Survey round was adjusted for in all regression models. The assumption of proportional odds in the final multivariable ordinal regression models was examined using Brant test [15]. As the surveys in government and FBO hospitals were conducted in different years all analyses were stratified by hospital ownership. The results from the multivariable models are presented as adjusted odds ratio (aOR) with $P$-values and $95 \%$ confidence intervals (CI). All analyses were conducted using Stata version 14 (StataCorp, College Station, TX, USA). Hypothesis testing and $\mathrm{CI}$ estimations were done with significance level of 0.05 .

\section{Results}

\section{Characteristics of study health workers}

Table 2 presents characteristics of 367 and 330 health workers respectively interviewed at the government and FBO hospitals. In both sectors, most health workers were female, younger than 35 years, having less than 5 years of inpatient experience and working in low malaria risk areas. Nurses and clinicians as well as paediatric and medical ward health workers were similarly represented within and between hospital sectors. Compared to FBO sector, government health workers were however more commonly female $(61.9 \%$ vs $51.2 \%)$, older than 35 years (37.6\% vs $17.3 \%$ ) and with more than 5 years of experience $(43.9 \%$ vs $24.5 \%)$. Regarding the exposure to the relevant interventions, over three-quarters of health workers in both sectors worked at hospitals with artesunate in stock however, only about a third had access to malaria guidelines and less than a quarter received inservice malaria case-management training and supportive supervision in past 3 months (Table 2). While only minor differences were observed between the sectors

\section{Table 1 Categories of the knowledge outcomes and study definitions}

\begin{tabular}{|c|c|c|c|}
\hline Knowledge outcomes & National recommendations & $\begin{array}{l}\text { Knowledge } \\
\text { categories }\end{array}$ & Category definitions \\
\hline \multirow[t]{3}{*}{ Treatment policy for severe malaria } & \multirow{3}{*}{$\begin{array}{l}\text { Artesunate for the following } 3 \text { severe } \\
\text { malaria populations } \\
\text { Children and non-pregnant adults; } \\
\text { Pregnant women in 1st trimester } \\
\text { Pregnant women in } 2 \text { nd \& } 3 \text { rd trimester }\end{array}$} & High & $\begin{array}{l}\text { Artesunate response for all } 3 \text { severe malaria } \\
\text { populations }\end{array}$ \\
\hline & & Medium & $\begin{array}{l}\text { Artesunate response for } 2 \text { severe malaria } \\
\text { populations }\end{array}$ \\
\hline & & Low & $\begin{array}{l}\text { Artesunate response for one or none of the } \\
\text { populations }\end{array}$ \\
\hline \multirow[t]{3}{*}{ Artesunate dose } & \multirow{3}{*}{$\begin{array}{l}2 \text { Weight categories } \\
3 \mathrm{mg} / \mathrm{kg} \text { for child }<20 \mathrm{~kg}, \\
2.4 \mathrm{mg} / \mathrm{kg} \text { for patient }>20 \mathrm{~kg}\end{array}$} & High & Correct response for 2 weight categories \\
\hline & & Medium & Correct response for one weight category \\
\hline & & Low & $\begin{array}{l}\text { No correct response for any of the weight } \\
\text { categories }\end{array}$ \\
\hline \multirow[t]{3}{*}{ Artesunate dosing interval } & \multirow{3}{*}{$\begin{array}{l}3 \text { dosing intervals } \\
12 \mathrm{~h} \text { between } 1 \mathrm{st} \text { and } 2 \mathrm{nd} \text { dose } \\
12 \mathrm{~h} \text { between } 2 \mathrm{nd} \text { and } 3 \mathrm{rd} \text { dose } \\
24 \mathrm{~h} \text { between } 3 \mathrm{rd} \text { and } 4 \text { th dose }\end{array}$} & High & Correct response for all 3 dosing intervals \\
\hline & & Medium & Correct response for 2 dosing intervals \\
\hline & & Low & $\begin{array}{l}\text { Correct response for one or none of the } \\
\text { dosing intervals }\end{array}$ \\
\hline \multirow[t]{3}{*}{ Artesunate preparation } & \multirow{3}{*}{$\begin{array}{l}\text { Solutions for } 2 \text { artesunate preparation steps } \\
\text { Bicarbonate for reconstitution } \\
\text { Saline or } 5 \% \text { dextrose for dilution }\end{array}$} & High & Correct response for 2 preparation steps \\
\hline & & Medium & Correct response for one preparation step \\
\hline & & Low & $\begin{array}{l}\text { No correct response for any of the prepara- } \\
\text { tion steps }\end{array}$ \\
\hline \multirow[t]{2}{*}{ Preferred route of artesunate administration } & \multirow[t]{2}{*}{ Intravenous slow bolus } & High & IV slow bolus response \\
\hline & & Low & Any other response \\
\hline
\end{tabular}


Table 2 Characteristics of study health workers

\begin{tabular}{|c|c|c|c|c|}
\hline \multirow[t]{3}{*}{ Health worker characteristics } & \multirow{2}{*}{\multicolumn{2}{|c|}{$\begin{array}{l}\begin{array}{l}\text { Government } \\
\text { hospitals }\end{array} \\
\mathrm{N}=367\end{array}$}} & \multirow{2}{*}{\multicolumn{2}{|c|}{$\begin{array}{l}\begin{array}{l}\text { Faith based } \\
\text { hospitals }\end{array} \\
\mathrm{N}=330\end{array}$}} \\
\hline & & & & \\
\hline & $\mathrm{n}$ & $\%$ & $\mathrm{n}$ & $\%$ \\
\hline \multicolumn{5}{|l|}{ Gender } \\
\hline Male & 140 & 38.1 & 161 & 48.8 \\
\hline Female & 227 & 61.9 & 169 & 51.2 \\
\hline \multicolumn{5}{|l|}{ Age (years) ${ }^{a}$} \\
\hline $35-70$ & 138 & 37.6 & 57 & 17.4 \\
\hline $21-35$ & 229 & 62.4 & 271 & 82.6 \\
\hline \multicolumn{5}{|l|}{ Pre-service training } \\
\hline Clinician & 175 & 47.7 & 156 & 47.3 \\
\hline Nurse & 192 & 52.3 & 174 & 52.7 \\
\hline \multicolumn{5}{|l|}{ Inpatient experience (years) ${ }^{b}$} \\
\hline$<5$ & 203 & 55.8 & 249 & 75.5 \\
\hline$>5$ & 161 & 44.2 & 81 & 24.5 \\
\hline \multicolumn{5}{|l|}{ Ward allocation } \\
\hline Paediatric & 185 & 50.4 & 168 & 50.9 \\
\hline Medical & 182 & 49.6 & 162 & 49.1 \\
\hline \multicolumn{5}{|l|}{ Malaria endemicity } \\
\hline High & 102 & 27.8 & 88 & 26.7 \\
\hline Low & 265 & 72.2 & 242 & 73.3 \\
\hline \multicolumn{5}{|l|}{ Exposure to artesunate interventions } \\
\hline Case management training & 87 & 23.7 & 66 & 20.0 \\
\hline Malaria guideline & 118 & 32.2 & 131 & 39.7 \\
\hline Supportive supervision & 39 & 10.6 & 29 & 8.8 \\
\hline Artesunate administration poster & 224 & 61.0 & 157 & 47.6 \\
\hline Artesunate in stock & 276 & 75.2 & 257 & 77.9 \\
\hline
\end{tabular}

a Denominator excludes 2 health workers with missing information in faithbased hospitals

b Denominator excludes 3 health workers with missing information in government hospitals

with respect to the training and supervision, government health workers however less commonly had access to malaria guidelines $(32.2 \%$ vs $39.8 \%)$ but more frequently worked in wards with displayed artesunate administration poster (61.0\% vs $47.0 \%)$.

\section{Knowledge of artesunate-based severe malaria treatment recommendations}

Table 3 shows the correctness of health workers' knowledge about artesunate-based severe malaria treatment recommendations stratified by hospital ownership and knowledge categories. Among respective government and FBO health workers, about a third of health workers had high knowledge of artesunate treatment policies $(30.8 \%$ vs $32.9 \%)$, a third knew all dosing intervals (33.5\% vs $33.3 \%)$, about half knew preparation solutions (49.9\% vs $55.8 \%$ ), half to two-thirds knew artesunate dose for both weight categories (50.8\% vs $66.7 \%$ ) and over
Table 3 Health workers' knowledge about artesunatebased severe malaria treatment recommendations

\begin{tabular}{|c|c|c|c|c|}
\hline \multirow[t]{3}{*}{$\begin{array}{l}\text { Health workers' } \\
\text { knowledge }\end{array}$} & \multirow{2}{*}{\multicolumn{2}{|c|}{$\begin{array}{l}\text { Government hospitals } \\
\overline{N=367}\end{array}$}} & \multirow{2}{*}{\multicolumn{2}{|c|}{$\begin{array}{l}\text { Faith based } \\
\text { hospitals } \\
N=330\end{array}$}} \\
\hline & & & & \\
\hline & $\mathbf{n}$ & $\%$ & $\mathrm{n}$ & $\%$ \\
\hline \multicolumn{5}{|c|}{ Treatment policy for severe malaria ${ }^{a}$} \\
\hline High & 113 & 30.8 & 108 & 32.9 \\
\hline Medium & 131 & 35.7 & 101 & 30.8 \\
\hline Low & 123 & 33.5 & 119 & 36.3 \\
\hline \multicolumn{5}{|l|}{ Artesunate dose $e^{b}$} \\
\hline High & 186 & 50.8 & 220 & 66.7 \\
\hline Medium & 100 & 27.3 & 67 & 20.3 \\
\hline Low & 80 & 21.9 & 43 & 13.0 \\
\hline \multicolumn{5}{|c|}{ Artesunate dosing intervals } \\
\hline High & 123 & 33.5 & 110 & 33.3 \\
\hline Medium & 136 & 37.1 & 137 & 41.5 \\
\hline Low & 108 & 29.4 & 83 & 25.2 \\
\hline \multicolumn{5}{|c|}{ Artesunate preparation } \\
\hline High & 183 & 49.9 & 184 & 55.8 \\
\hline Medium & 134 & 36.5 & 114 & 34.5 \\
\hline Low & 50 & 13.6 & 32 & 9.7 \\
\hline \multicolumn{5}{|c|}{ Preferred route of administration } \\
\hline High & 289 & 78.7 & 272 & 82.4 \\
\hline Low & 78 & 21.3 & 58 & 17.6 \\
\hline
\end{tabular}

a Denominator excludes 2 health workers with missing information in faithbased hospitals

b Denominator excludes 1 health worker with missing information in government hospitals

three-quarters knew the preferred route of administration $(78.7 \%$ vs $82.4 \%)$.

\section{Predictors of health workers knowledge about treatment recommendations}

Tables in Additional files 1, 2, 3, 4, 5 show the results of univariable logistic regression analyses examining association between 11 factors and five knowledge outcomes about artesunate-based severe malaria treatment recommendations for each of the two hospital ownership sectors. In the government sector all 11 factors met the selection criteria of $\mathrm{P}<0.15$ for multivariable analyses on at least one knowledge outcome while in the FBO sector it was only health workers' ward allocation that did not meet the same entrance criteria on any of the examined outcomes. For each of the knowledge outcomes, the multivariable results for the government and FBO hospitals are shown in Tables 4 and 5 , respectively.

With respect to the treatment policy knowledge, clinicians compared to nurses were more likely to have high knowledge, both at the government $(\mathrm{aOR}=1.86 ; 95 \%$ CI 1.18-2.91) and FBO hospitals $(\mathrm{aOR}=2.27 ; 95 \% \mathrm{CI}$ 
1.41-3.65). In the government hospitals, health worker's treatment policy knowledge was also significantly associated with training exposure $(\mathrm{aOR}=2.31 ; 95 \% \mathrm{CI}$ $1.44-3.72)$ and follow-up surveys $(\mathrm{aOR}=1.83 ; 95 \% \mathrm{CI}$ 1.22-2.74) while at the FBO hospitals the artesunate availability $(\mathrm{aOR}=2.01 ; 95 \% \mathrm{CI} 1.05-3.85)$ and access to guidelines $(\mathrm{aOR}=2.41 ; 95 \% \mathrm{CI} 1.48-3.93)$ were significant predictors.

Health workers' knowledge about recommended artesunate dosing was significantly associated with displayed artesunate administration posters $(\mathrm{aOR}=2.17$; 95\% CI 1.24-3.79), among paediatric compared to medical ward health workers $(\mathrm{aOR}=1.99 ; 95 \% \mathrm{CI} 1.30-3.04)$ and during the follow-up compared to the baseline survey $(\mathrm{aOR}=2.01 ; 95 \% \mathrm{CI} 1.28-3.16)$ within government hospitals. At the FBO hospitals, only health workers' cadre was significant where clinicians were more likely to have correct dosing knowledge than nurses $(\mathrm{aOR}=2.24$; 95\% CI 1.33-3.77). Regarding the knowledge of artesunate dosing intervals, the availability of artesunate $(\mathrm{aOR}=2.18 ; 95 \%$ CI $1.20-3.94)$ and health workers' cadre (aOR: 1.76; 95\% CI 1.15-2.69) were significantly associated at the FBO hospitals while at the government hospitals the only significant predictor was the follow up compared to baseline survey $(\mathrm{aOR}=1.55 ; 95 \% \mathrm{CI}$ $1.02-2.37)$.

The knowledge of preferred artesunate administration route via intravenous slow bolus was significantly higher in high compared to low malaria risk areas, both among government $(\mathrm{aOR}=2.97 ; 95 \% \mathrm{CI} 1.04-8.46)$ and $\mathrm{FBO}$ health workers $(\mathrm{aOR}=5.79 ; 95 \% \mathrm{CI} 1.17-28.67)$. Furthermore, the same knowledge outcome was associated with displayed artesunate posters $(\mathrm{aOR}=2.19$; $95 \%$ CI 1.05 4.57) in the government hospitals and the artesunate availability $(\mathrm{aOR}=4.73$; 95\% CI $1.50-14.89)$ in FBO hospitals. Finally, only one significant predictor, paediatric compared to medical ward allocation ( $\mathrm{aOR}=1.99 ; 95 \%$ CI 1.33-2.99) at the government hospitals was associated with the knowledge about artesunate preparation.

\section{Discussion}

Five years following the change of national policy in Kenya, the knowledge of inpatient health workers about artesunate-based severe malaria treatment recommendations was suboptimal, both at the government and FBO hospitals. The analysis examining 11 factors of five knowledge outcomes in the two hospital sectors reveals several patterns of importance for artesunate policy implementers in Kenya and other African countries.

In-service training, commonly used intervention for knowledge translation, was found to be associated with higher knowledge about the new severe malaria treatment policy among government health workers, however, without an effect on the subtler artesunate treatment standards, such as correct knowledge about dosing, dosing intervals, drug preparation and preferred route of administration. A similar pattern was revealed at the FBO hospitals with respect to health workers' exposure to malaria guidelines. Lack of training and guideline association with health workers' knowledge has been reported in Kenya [16], elsewhere in Africa [17-19] and limited beneficial effects observed in this study may reflect the short time allocated to severe malaria topic (only $2-3 \mathrm{~h}$ ) within the 3-day malaria case management training curriculum, lack of guideline suitability to transfer more subtle knowledge information, or eventually suboptimal quality of implementation when interventions, such as in-service training, are delivered programmatically on a large, national scale $[19,20]$.

In contrast to training and access to guidelines, the correct dosing knowledge was associated with simple job aids such as displayed posters focusing on recommended artesunate dosing, preparation and administration within the wards. The results concur with the study showing the effects of poster reminders on health workers surveillance knowledge in Kenya [16]. Interestingly, the effects of such job-aids are observed within the government sector while at the FBO hospitals commodity availability seems to be a prevailing contextual determinant, both of the treatment policy and artesunate use knowledge. Lack of access to subsidized artesunate by FBO hospitals may be a factor underlying knowledge deficiencies at the hospitals where absence of artesunate is unlikely due to experienced stock-outs, but more likely the result of failed implementation due to high cost of artesunate.

Clinicians compared to nurses had higher knowledge levels. The pre-service training effect, given the nonprescribing role of nurses in the inpatient setting, was expectedly marked regarding the drug policy knowledge and correct dosing. Higher artesunate preparation knowledge was however not found among nurses, the cadre routinely performing this task in the hospital inpatient setting. This was not also observed in Tanzania where artesunate preparation knowledge was higher among clinicians compared to nurses [13]. What has been however observed in the study reported in this manuscript is higher artesunate preparation and dosing knowledge among paediatric ward health workers at the government hospitals, the findings likely reflecting greater traditional focus towards paediatric malaria care $[21,22]$. Future interventions should pay greater attention to the health workers managing adult patients in the medical wards.

Follow up surveys at the government hospitals have been associated with correct knowledge about the treatment policy and recommended dosing despite 


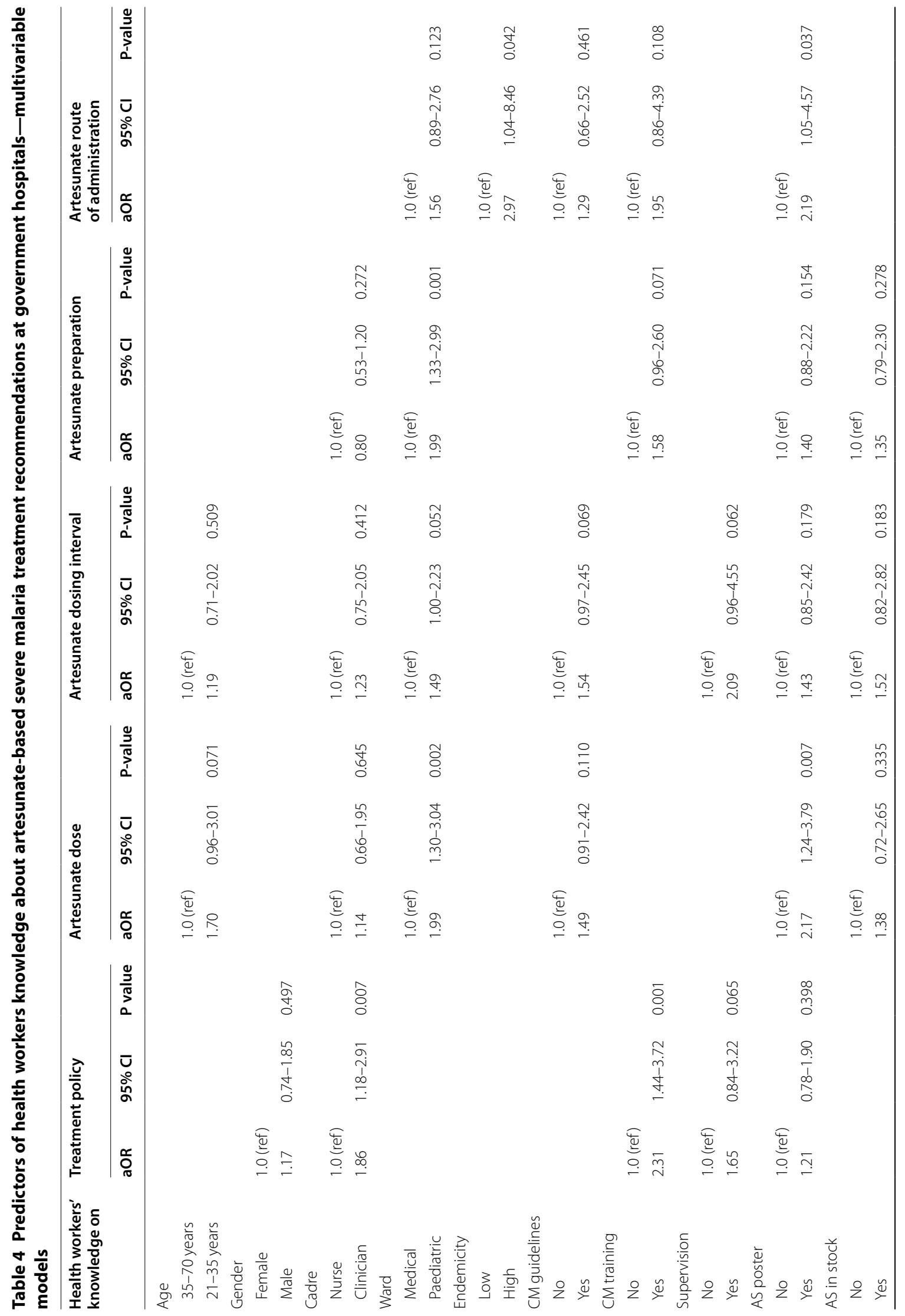




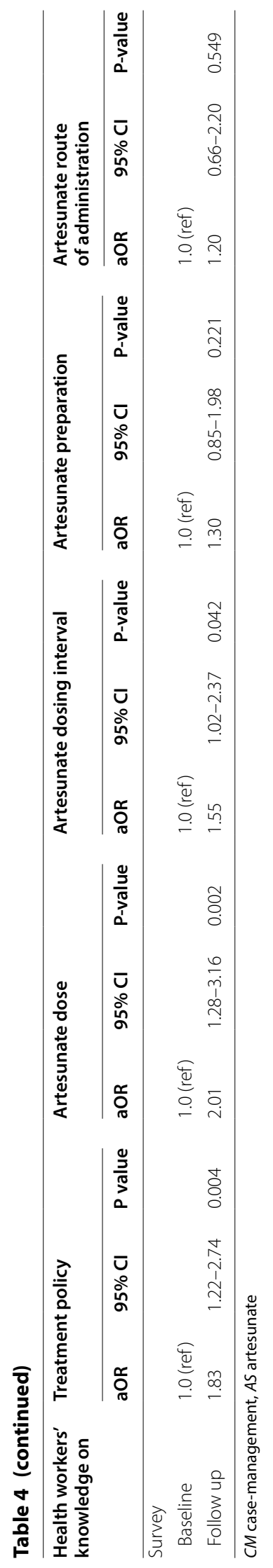




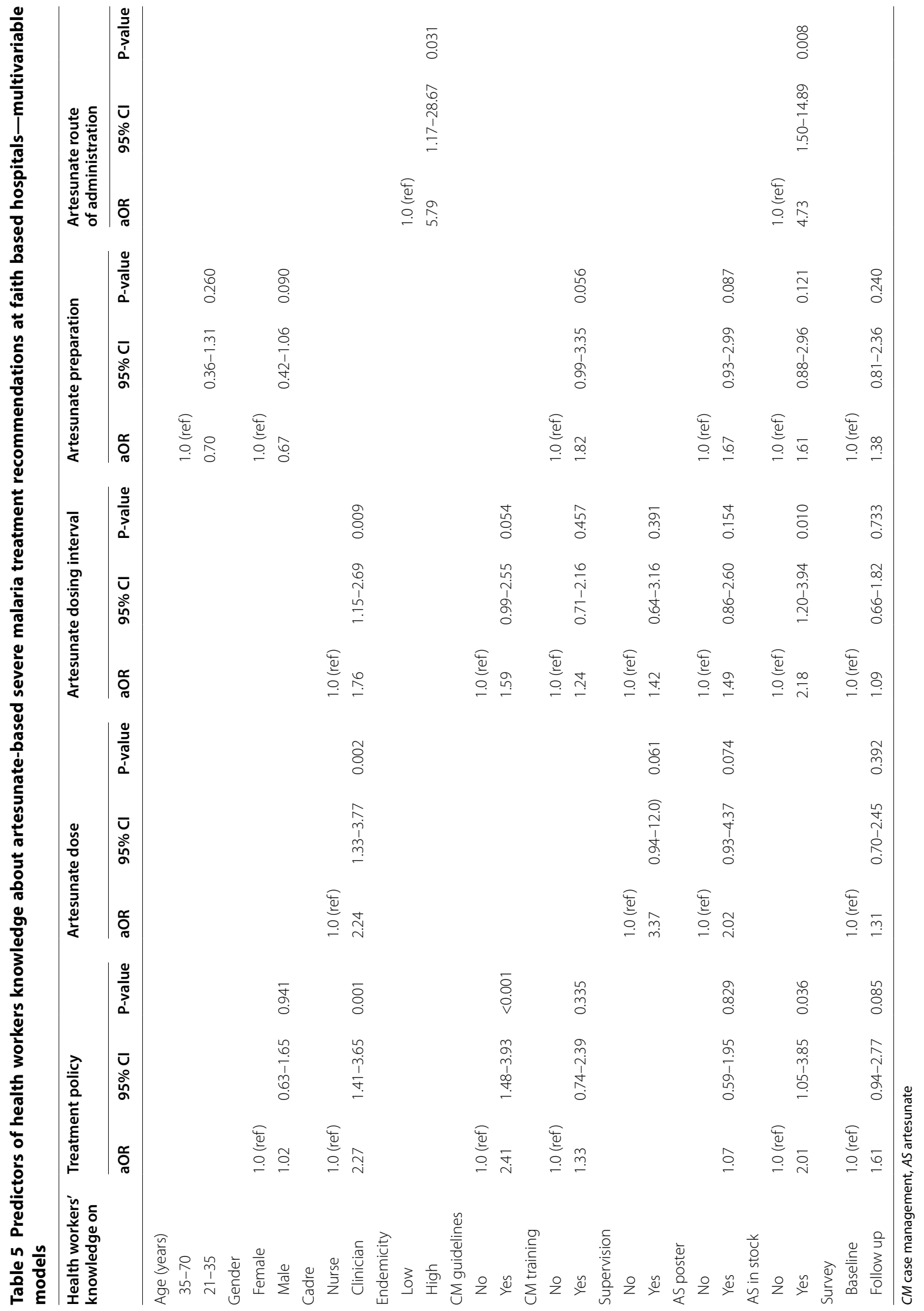


small proportion of less than $5 \%$ of health workers being repeatedly interviewed. Provision of correct responses after the knowledge assessments, dissemination of national malaria guidelines, and display of artesunate posters including informal consultations between the interviewed health workers and the study personnel does suggest that surveys at the study hospitals may not present only measurement and monitoring activity, but also have an intervention effect per se.

Finally, few limitations should be mentioned. First, while knowledge about the new treatment policy does present basic pre-requisite for the drug policy implementation the results of this study do not reflect actual clinical practices. Second, while these results apply to major government and FBO hospitals nationally they do not reflect knowledge and determinants at smaller facilities with inpatient capacities. Finally, some of the significant associations may have not been observed due to power limitations while conversely multiple comparisons performed may have resulted in some of the associations being due to chance.

\section{Conclusions}

Programmatic interventions ensuring display of artesunate administration posters in the wards, targeting of health workers managing adult patients in the medical wards and repeated knowledge assessments are likely to be beneficial for improving the knowledge of government health workers about artesunate-based severe malaria treatment recommendations. The availability of artesunate and focus on improvements of nurses' knowledge should be prioritized at the FBO hospitals.

\section{Supplementary information}

Supplementary information accompanies this paper at https://doi. org/10.1186/s12936-020-03341-2.

Additional file 1. Univariable ordinal logistic regression analysis of predictors of knowledge on severe malaria treatment policy, by hospital ownership.

Additional file 2. Univariable ordinal logistic regression analysis of predictors of artesunate dose knowledge, by hospital ownership.

Additional file 3. Univariable ordinal logistic regression analysis of predictors of artesunate dosing interval knowledge, by hospital ownership.

Additional file 4. Univariable ordinal logistic regression analysis of predictors of artesunate preparation knowledge, by hospital ownership.

Additional file 5. Univariable binary logistic regression analysis of predictors of the knowledge about preferred route of artesunate, by hospital ownership.

\section{Abbreviations}

aOR: Adjusted odds ratio; Cl: Confidence interval; FBO: Faith-based organization; WHO: World Health Organization.

\section{Acknowledgements}

The authors would like to thank the Division of National Malaria Programme and the County Health Management Teams for their support on this study. We also thank the hospital nurses and clinicians who participated in the study.

\section{Authors' contributions}

$\mathrm{BM}, \mathrm{DZ}, \mathrm{HK}$ and TNOA designed the study. All authors contributed to the analysis and interpretation of the study findings. BM wrote the first draft of the manuscript. All authors read and approved the final manuscript.

\section{Funding}

Funding for malaria case-management surveys are provided by the Global Fund to Fight AIDS, Tuberculosis and Malaria. R.W.S. is funded by Wellcome Trust Principal Fellowship (\# 212176). BA is grateful for the support from the KEMRI-Wellcome Trust/Open University collaboration and for funding support under the IDeAL Project (number 107769). DZ, LM, BA, and R.W.S. acknowledge the support of the Wellcome Trust to the Kenya Major Overseas Programme (\# 203077).

\section{Availability of data and materials}

The datasets used and analyzed during the current study are available from the corresponding author on reasonable request.

\section{Ethics approval and consent to participate}

This study was approved by Kenyatta National Hospital/University of NairobiEthics Committee (KNH/UON/ERC/P233/04/2018). Written informed consent was obtained from all health workers interviewed in the study.

\section{Consent for publication}

Not applicable.

\section{Competing interests}

The authors declare that they have no competing interests.

\section{Author details}

${ }^{1}$ University of Nairobi, Institute of Tropical and Infectious Diseases, Nairobi, Kenya. ${ }^{2}$ Division of National Malaria Programme, Ministry of Health, Nairobi, Kenya. ${ }^{3}$ KEMRI-Welcome Trust Research Programme, Nairobi, Kenya. ${ }^{4}$ Centre for Tropical Medicine and Global Health, University of Oxford, Oxford, UK. ${ }^{5}$ World Health Organization, Nairobi, Kenya. ${ }^{6}$ School of Mathematics and Computer Science, University of Kwa Zulu Natal, Durban, South Africa.

Received: 13 February 2020 Accepted: 17 July 2020

Published online: 23 July 2020

\section{References}

1. Snow RW, Kibuchi E, Karuri SW, Sang G, Gitonga CW, Mwandawiro C, et al. Changing malaria prevalence on the Kenyan Coast since 1974: climate, drugs and vector control. PLOS ONE. 2015;10:e0128792.

2. Macharia PM, Giorgi E, Noor AM, Waqo E, Kiptui R, Okiro EA, et al. Spatiotemporal analysis of Plasmodium falciparum prevalence to understand the past and chart the future of malaria control in Kenya. Malar J. 2018;17:340.

3. Akech S, Chepkirui M, Ogero M, Agweyu A, Irimu G, English M, et al. The clinical profile of severe paediatric malaria in an area targeted for routine RTS, S/AS01 malaria vaccination in Western Kenya. Clin Infect Dis. 2019;71:372-80.

4. WHO. Management of severe malaria A practical handbook. 3rd ed. Geneva: World Health Organization; 2012.

5. Ministry of Health. National guidelines for diagnosis, treatment and prevention of malaria for health workers. 4 th ed. Nairobi: Division of Malaria Control; 2012.

6. Ministry of Health. Participants manual for diagnosis, management and prevention of malaria for health workers. Nairobi: National Malaria Contro Programme; 2012.

7. Ministry of Health. Guidelines for administration of injectable artesunate for severe malaria. Nairobi: National Malaria Control Programme; 2015.

8. Ouma PO, Maina J, Thuranira PN, Macharia PM, Alegana VA, English M, et al. Access to emergency hospital care provided by the public sector 
in sub-Saharan Africa in 2015: a geocoded inventory and spatial analysis. Lancet Glob Health. 2018;6:e342-50.

9. Lomas J, Anderson GM, Domnick-Pierre K, Vayda E, Enkin MW, Hannah WJ. Do practice guidelines guide practice? The effect of a consensus statement on the practice of physicians. N Engl J Med. 1989;321:1306-11.

10. Berhe DF, Taxis K, Haaijer-Ruskamp FM, Mol PGM. Healthcare professionals' level of medication knowledge in Africa: a systematic review. Br J Clin Pharmacol. 2018;84:2729-46.

11. Yoo JY, Kim JH, Kim JS, Kim HL, Ki JS. Clinical nurses' beliefs, knowledge, organizational readiness and level of implementation of evidence-based practice: the first step to creating an evidence-based practice culture PLOS ONE. 2019;14:e226742.

12. Zurovac D, Machini B, Kiptui R, Memusi D, Amboko B, Kigen S, et al. Monitoring health systems readiness and inpatient malaria case-management at Kenyan county hospitals. Malar J. 2018;17:213.

13. Mikomangwa WP, Kaaya C, Kilonzi M, Mlyuka H, Marealle Al, Mutagonda R. Level of knowledge among health care providers on preparation of injectable artesunate for treatment of severe malaria in public health facilities in Tanzania. BMC Res Notes. 2019;12:224.

14. National Malaria Control Programme, Kenya National Bureau of Statistics, ICF International. Kenya Malaria Indicator Survey 2015. Nairobi; 2016.

15. Brant R. Assessing proportionality in the proportional odds model for ordinal logistic regression. Biometrics. 1990;46:1171-8.

16. Toda M, Zurovac D, Njeru I, Kareko D, Mwau M, Morita K. Health worker knowledge of Integrated Disease Surveillance and Response standard case definitions: a cross-sectional survey at rural health facilities in Kenya. BMC Public Health. 2018;18:146.

17. Shayo EH, Våga BB, Moland KM, Kamuzora P, Blystad A. Challenges of disseminating clinical practice guidelines in a weak health system: the case of HIV and infant feeding recommendations in Tanzania. Int Breastfeed J. 2014;9:188.

18. Jinadu KA, Adebiyi AO, Sekoni OO, Bamgboye EA. Integrated disease surveillance and response strategy for epidemic prone diseases at the primary health care (PHC) level in Oyo State, Nigeria: what do health care workers know and feel? Pan Afr Med J. 2018;31:19.

19. The Health Communication Capacity Collaborative (HC3). Factors Impacting the Effectiveness of Health Care Worker Behavior Change: A Literature Review. Baltimore: Johns Hopkins Center for Communication Programs; 2016.

20. Eboreime EA, Eyles J, Nxumalo N, Eboreime OL, Ramaswamy R. Implementation process and quality of a primary health care system improvement initiative in a decentralized context: a retrospective appraisal using the quality implementation framework. Int J Health Plann Manage. 2019;34:e369-86.

21. Murray CJ, Rosenfeld LC, Lim SS, Andrews KG, Foreman KJ, et al. Global malaria mortality between 1980 and 2010: a systematic analysis. Lancet. 2012;79:413-31.

22. Desai M, Buff AM, Khagayi S, Byass P, Amek N, van Eijk A, et al. Agespecific malaria mortality rates in the KEMRI/CDC health and demographic surveillance system in western Kenya, 2003-2010. PLoS ONE. 2014;9:e106197.

\section{Publisher's Note}

Springer Nature remains neutral with regard to jurisdictional claims in published maps and institutional affiliations.
Ready to submit your research? Choose BMC and benefit from:

- fast, convenient online submission

- thorough peer review by experienced researchers in your field

- rapid publication on acceptance

- support for research data, including large and complex data types

- gold Open Access which fosters wider collaboration and increased citations

- maximum visibility for your research: over $100 \mathrm{M}$ website views per year

At BMC, research is always in progress.

Learn more biomedcentral.com/submissions 